\title{
Polypharmacy, benzodiazepines, and antidepressants, but not antipsychotics, are associated with increased falls risk in UK care home residents: a prospective multi-centre study
}

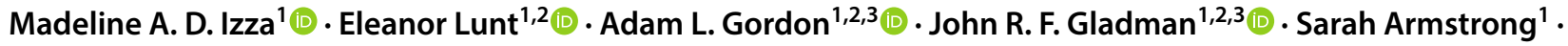 \\ Pip Logan ${ }^{1,2,3,4}$
}

Received: 30 May 2020 / Accepted: 30 July 2020 / Published online: 19 August 2020

(c) The Author(s) 2020

\section{Key summary points}

Aim To explore the link between polypharmacy, psychotropic medications, and falls risk in a cohort of UK care home residents.

Findings Polypharmacy and psychotropic drugs are predictive of falls in UK care home residents.

Message Deprescribing interventions relating to psychotropic drugs should continue to be encouraged.

\begin{abstract}
Purpose Falls and polypharmacy are both common in care home residents. Deprescribing of medications in residents with increased falls risk is encouraged. Psychotropic medications are known to increase falls risk in older adults. These drugs are often used in care home residents for depression, anxiety, and behavioural and psychological symptoms of dementia. However, a few studies have explored the link between polypharmacy, psychotropic medications, and falls risk in care home residents.

Methods This was a prospective cohort study of residents from 84 UK care homes. Data were collected from residents' care records and medication administration records. Age, diagnoses, gender, number of medications, and number of psychotropic medications were collected at baseline and residents were monitored over three months for occurrence of falls. Logistic regression models were used to assess the effect of multiple medications and psychotropic medication on falls whilst adjusting for confounders.

Results Of the 1655 participants, mean age 85 (SD 8.9) years, 67.9\% female, 519 (31\%) fell in 3 months. Both the total number of regular drugs prescribed and taking $\geq 1$ regular psychotropic medication were independent risk factors for falling (adjusted odds ratio (OR) 1.06 (95\% CI 1.03-1.09, $p<0.01$ ) and 1.39 (95\% CI 1.10-1.76, $p<0.01$ ), respectively). The risk of falls was higher in those taking antidepressants $(p<0.01)$ and benzodiazepines $(p<0.01)$ but not antipsychotics $(p>0.05)$. Conclusion In UK care homes, number of medications and psychotropic medications (particularly antidepressants and benzodiazepines) predicted falls. This information can be used to inform prescribing and deprescribing decisions.
\end{abstract}

Keywords Residential facilities $\cdot$ Accidental falls $\cdot$ Polypharmacy $\cdot$ Psychotropic medications

Madeline A. D. Izza

mzymai@nottingham.ac.uk

1 School of Medicine, University of Nottingham, Nottingham, UK

2 Nottingham NIHR Biomedical Research Centre Musculoskeletal Theme, Nottingham, UK

3 NIHR Applied Research Collaboration East Midlands (ARC-EM), Nottingham, UK

4 Nottingham CityCare Partnership, Nottingham, UK

\section{Introduction}

Falls are associated with polypharmacy and psychotropic drug use. Taking four or more medications is associated with increased fall rates by $18 \%$ in those over the age of 60 [1]. Older people living at home who take psychotropic drugs are up to 1.62 times more likely to fall [2]. These associations are often used to justify routine medication reviews and deprescribing in older people at risk of falls [3]. 
Falls incidence in older people living in care homes is three times that of those living at home. Contributors include physical frailty, cognitive impairment, comorbidities, and polypharmacy, which are all more prevalent in care homes [4]. Psychotropic medications (including, antipsychotics, anxiolytics, hypnotics, and antidepressants) are more commonly prescribed for care home residents because of underlying dementia, depression, and behavioural symptoms [5, 6]. The average UK care home resident takes eight medications, which could place them at increased risk of falls, although association between falls and medications in this group has been less widely studied than community populations $[2,7]$.

Polypharmacy and psychotropic drug use might be expected to show a similar association with falls in care home and community-dwelling populations. However, the risk factors for falls in care homes may differ from the wider population, and the association between falls, polypharmacy, and psychotropic drug use may differ accordingly. Doctors may be tempted to prescribe psychotropic medications to reduce behaviours such as wandering, which are felt to be risk factors for falls, or they may be unsure about the size of risk of falls associated with them. Psychotropic drug prescriptions in Dutch Nursing Home residents are associated with a threefold increase in falls risk [8]. Dutch Nursing Homes are, though, organised differently from UK care homes and, importantly, have differing practises regarding physical restraint-so associations seen in one country may not be replicated elsewhere [9].

To provide clarity on this topic and support better clinical decision-making, we examined the relationship between falls, polypharmacy and psychotropic drug use, using data from a large cluster randomised controlled trial of a multifactorial falls prevention programme in care homes (FinCH). The study objectives were to determine if polypharmacy and psychotropic medications increased the risk of falls in UK care home residents.

\section{Methods}

The Falls in Care Home (FinCH) study was a multi-centre cluster randomised controlled trial investigating the efficacy of the Guide to Action Care Home (GtACH) fall prevention programme. It was conducted between 2016 and 2019 in 84 UK care homes. The full protocol has been published [10]. Ethical approval was provided by the Yorkshire \& The Humber-Bradford Leeds Research Ethics Committee (REC: $16 / \mathrm{YH} / 0111$ ). Permission to use data for the sub-analysis presented here was granted by the Trial Steering committee, shown in "Appendix A". Informed consent for the trial was obtained from participants, or a consultee if participants lacked capacity.
This sub-analysis considers the baseline 3 month period prior to randomisation and hence before exposure to any study-related intervention which might have changed falls or medication management. Data collection took place in the 18 months between August 2016 and February 2018.

Data were collected from care home records on age, gender, and medical diagnoses. Medications were recorded from care home Medicine Administration Record (MAR) charts. Eye drops and nasal sprays were included, because they are often systemically absorbed and may contribute to drug interactions. Over-the-counter (OTC) medications were included. Pro re nata (PRN) medications (taken as needed) were analysed separately for their contribution to medication burden. Medical equipment and dressings, topical medications (except eye drops and nasal sprays), vaccinations, and dietary supplements were excluded. Medication inclusion or exclusion decisions were considered independently by two researchers to minimise error. The Anatomical Therapeutic Chemical (ATC) classification system was used to classify psychotropic drugs and create an adapted version of the classification used by Cox et al. [8]. This classification and the psychotropic drugs prescribed are shown in "Appendix B". Polypharmacy was defined as taking five or more medications based on prior work which shows a strong association with falls at this level [11]. Falls incidence over the 3 month observation period was the outcome variable. Falls were defined as "an unexpected event in which the participants come to rest on the ground, floor, or lower level" [12]. Due to uncertainty associated with unwitnessed falls, if a resident was found on the floor, it was assumed that they had fallen. Falls data were collated from care home records and incident report forms, both of which have been previously validated as reliable sources [13].

Demographic, medication, and falls data for each participant in the baseline period were imported into Microsoft Excel 2016. Falls without a date were excluded. Where medication data were affected by spelling errors, they were included only if an agreement was established between two medically trained members of the research team over which drug was intended.

Descriptive statistics were calculated for the total population, fallers and non-fallers. Categorical data were expressed as frequencies and percentages. Histograms were used to determine distribution and continuous data were expressed as means with standard deviations (SDs) if normally distributed, or medians with interquartile ranges (IQRs) if nonparametric. Any data identified as extreme outliers were removed. Odds ratios and mean differences were calculated to determine the significant characteristics between fallers and non-fallers.

A logistic regression model with the dichotomous dependent variable of faller or non-faller and the continuous predictor variable of number of drugs (as a measure of 
polypharmacy) was fitted. Demographic data were included as predictors in the model to control for possible confounders. A further binary logistic regression was performed using the same dichotomous dependent variable and adding in whether the participant was on psychotropic drug(s) or not as a categorical predictor variable. Each regression analysis was performed twice, with and without PRN drugs. A $p$ value $<0.05$ was considered significant. All statistical analyses were carried out using Statistical Package for Social Sciences (SPSS, version 24.0, IBM Corporation, Armonk, NY).

\section{Results}

\section{Study population}

Data from 1655 participants were analysed, with characteristics summarised in Table 1. The mean age of participants was 85 years (SD 8.9). Approximately two-thirds of the population were female. Dementia was the most prevalent diagnosis with 1112 residents $(67 \%)$ diagnosed with the condition.

A total of 3671 (26\%) medications listed in the MAR were removed due to exclusion criteria and 14 due to indecipherable spelling errors, leaving 10,226 medications used by the population which were then analysed. The median number of drugs prescribed per resident was 6 (IQR 3-9)
Table 1 Characteristics of study population, showing the total population and the differences between fallers and non-fallers

\begin{tabular}{|c|c|c|c|c|c|}
\hline & $\begin{array}{l}\text { Total population } \\
N=1655\end{array}$ & $\begin{array}{l}\text { Fallers } \\
N=519\end{array}$ & $\begin{array}{l}\text { Non-fallers } \\
N=1136\end{array}$ & $\begin{array}{l}\text { Univariate analysis } \\
\text { OR }(95 \% \mathrm{CI})\end{array}$ & $P$ value \\
\hline Age & $85.0(\mathrm{SD} 8.9)$ & $85.8(\mathrm{SD} 8.1)$ & 84.7 (SD 9.2) & $1.10(0.18-2.02)^{\mathrm{a}}$ & 0.019 \\
\hline \multicolumn{6}{|l|}{ Gender } \\
\hline Female & $1,123(67.9 \%)$ & $329(63.4 \%)$ & $794(69.9 \%)$ & & \\
\hline Male & $532(32.1 \%)$ & $190(36.6 \%)$ & $342(30.1 \%)$ & $1.34(1.08-1.67)$ & 0.008 \\
\hline \multicolumn{6}{|l|}{ Diagnoses } \\
\hline Dementia & $1112(67.2 \%)$ & $386(74.4 \%)$ & $726(63.9 \%)$ & $1.64(1.30-2.06)$ & $<0.001$ \\
\hline Diabetes & $321(19.4 \%)$ & $98(18.9 \%)$ & $223(19.6 \%)$ & $0.95(0.73-1.24)$ & 0.721 \\
\hline Stroke & $262(15.8 \%)$ & $81(15.6 \%)$ & $181(15.9 \%)$ & $0.97(0.73-1.30)$ & 0.866 \\
\hline Coronary heart disease & $235(14.2 \%)^{\mathrm{b}}$ & $73(14.1 \%)$ & $162(14.3 \%)^{\mathrm{b}}$ & $0.98(0.73-1.32)$ & 0.910 \\
\hline \multicolumn{6}{|l|}{ Number of drugs } \\
\hline Without PRN & 6 (IQR 3-9) & 6 (IQR 4-9) & 6 (IQR 3-8) & & $<0.001$ \\
\hline Including PRN & 7 (IQR 4-10) & 8 (IQR 5-11) & 7 (IQR 4-10) & & $<0.001$ \\
\hline \multicolumn{6}{|c|}{ Number of residents on polypharmacy ${ }^{c}$} \\
\hline Without PRN & $1,024(61.9 \%)$ & $350(67.4 \%)$ & $674(59.3 \%)$ & $1.42(1.14-1.77)$ & 0.002 \\
\hline Including PRN & $1,164(70.3 \%)$ & $398(76.7 \%)$ & $766(67.4 \%)$ & $1.59(1.25-2.02)$ & $<0.001$ \\
\hline \multicolumn{6}{|c|}{ Number of residents taking psychotropic drug(s) } \\
\hline Without PRN & $816(49.3 \%)$ & $295(56.8 \%)$ & $521(45.9 \%)$ & $1.55(1.26-1.92)$ & $<0.001$ \\
\hline Including PRN & $870(52.6 \%)$ & $307(59.2 \%)$ & $563(49.6 \%)$ & $1.47(1.19-1.82)$ & $<0.001$ \\
\hline \multicolumn{6}{|c|}{ Number of residents taking antidepressant(s) } \\
\hline Without PRN & $613(37 \%)$ & $219(42.2 \%)$ & $394(34.7 \%)$ & $1.37(1.11-1.70)$ & 0.003 \\
\hline Including PRN & $614(37.1 \%)$ & $219(42.2 \%)$ & $395(34.8 \%)$ & $1.37(1.12-1.69)$ & 0.004 \\
\hline \multicolumn{6}{|c|}{ Number of residents taking antipsychotic(s) } \\
\hline Without PRN & $251(15.2 \%)$ & $87(16.8 \%)$ & $164(14.4 \%)$ & $1.19(0.90-1.59)$ & 0.221 \\
\hline Including PRN & $278(16.8 \%)$ & $91(17.5 \%)$ & $187(16.5 \%)$ & $1.08(0.82-1.42)$ & 0.588 \\
\hline \multicolumn{6}{|c|}{ Number of residents taking benzodiazepine(s) } \\
\hline Without PRN & $207(12.5 \%)$ & $84(16.2 \%)$ & $123(10.8 \%)$ & $1.59(1.18-2.14)$ & 0.002 \\
\hline Including PRN & $329(19.9 \%)$ & $122(23.5 \%)$ & $207(18.2 \%)$ & $1.38(1.07-1.77)$ & 0.013 \\
\hline
\end{tabular}

Values are Mean (SD), Median (IQR) or Number (Proportion)

${ }^{a}$ Mean difference calculated for continuous data

${ }^{\mathrm{b}}$ In calculating coronary heart disease percentages $n=1654$ (Total population) and $n=1135$ (Non-Fallers) to account for missing data for one resident who did not fall

${ }^{\mathrm{c}}$ Polypharmacy $=\geq 5$ drugs 
Table 2 Logistic regression analysis assessing the predictive ability of number of drugs excluding PRN drugs on fall outcomes in care home residents

\begin{tabular}{llllr}
\hline Predictor & Odds ratio & \multicolumn{2}{c}{$95 \%$ CI for odds ratio } & $P$ \\
\cline { 3 - 4 } & & Lower & Upper & \\
\hline Constant & 0.033 & & & $<0.001$ \\
Age & 1.021 & 1.008 & 1.034 & 0.001 \\
Gender & 1.405 & 1.120 & 1.762 & 0.003 \\
Dementia & 1.749 & 1.382 & 2.213 & $<0.001$ \\
No. drugs & 1.058 & 1.031 & 1.086 & $<0.001$ \\
\hline
\end{tabular}

Note Cox \& Snell $R^{2}=0.031$, Nagelkerke $R^{2}=0.043$. Gender: $1=$ male, $0=$ female

excluding PRN. Polypharmacy (without PRN) was present in 1024 (62\%) participants. Regular psychotropic drug prescriptions were present in approximately half of the population $(49 \%)$.

\section{Polypharmacy and falls}

There were a total of 1188 falls in the population, with 519 residents having $\geq 1$ fall, in the 3 months. The first logistic regression model assessed the effect of the number of drugs (excluding PRN drugs), adjusting for gender, age, and dementia (Table 2). Further control for other demographics had no significant effect and was removed from the model. The model explained between $3.1 \%$ and $4.3 \%$ of variability in falls outcomes.

All four predictor variables made a significant contribution to the model. For every additional drug prescribed, the odds of falling increased by 1.058 times, after controlling for the other factors mentioned above. Older residents were more likely to fall than their younger counterparts. Men were predicted to fall more than women, and residents with dementia were predicted to fall $75 \%$ more than those without dementia. In the second binary logistic regression model the predictor effect including PRN drugs was tested, this found similar results to the previous model.

\section{Psychotropic medications and falls}

$816(49.3 \%)$ residents took regular psychotropic medications. In unadjusted analysis, psychotropic medications were associated with falls $(p<0.001)$. The risk of falls was higher in those taking antidepressants $(p<0.01)$ and benzodiazepines $(p<0.01)$ but not antipsychotics $(p>0.05)$.

A third binary logistic regression model assessed the effect of one or more psychotropic drugs excluding PRN drugs, and controlled for age, gender, dementia diagnosis, and number of drugs (Table 3). The adjusted odds ratio of taking one or more psychotropic drug on falls risk was 1.39
Table 3 Binary logistic regression analysis assessing the predictive ability of psychotropic drug(s) excluding those indicated as PRN, on fall outcomes in care home residents

\begin{tabular}{llllr}
\hline Predictor & Odds ratio & \multicolumn{2}{l}{$\begin{array}{l}\text { 95\% CI for odds } \\
\text { ratio }\end{array}$} \\
\cline { 3 - 4 } & & Lower & Upper & \\
\hline Constant & 0.027 & & & $<0.001$ \\
Age & 1.023 & 1.010 & 1.036 & 0.001 \\
Gender & 1.413 & 1.126 & 1.774 & 0.003 \\
Dementia & 1.686 & 1.330 & 2.138 & $<0.001$ \\
No. drugs & 1.041 & 1.011 & 1.071 & 0.006 \\
Psychotropic drug(s) & 1.392 & 1.100 & 1.762 & 0.006 \\
\hline
\end{tabular}

Note Cox \& Snell $R^{2}=0.035$, Nagelkerke $R^{2}=0.049$. Gender: $1=$ male, $0=$ female

(95\% CI 1.100-1.762, $p=0.006)$. All variables controlled for showed a similar significant effect as in previous models. Likewise, the number of drugs remained a significant predictor.

In the final model, the predictor effect of whether a resident was on one or more psychotropic drugs including PRN drugs was tested, this again yielded similar results to those excluding PRN.

\section{Discussion}

Polypharmacy and psychotropic prescriptions were both prevalent in care home residents, and both were associated with an increased falls risk. These findings were independent of age, gender, and dementia diagnosis.

An important strength of this study is the large and representative dataset of UK care home residents from the FinCH study trial. The age of residents in this study was similar to that in a previous representative cohort study on the health of UK care home residents [7]. The proportion of residents with dementia in this study is close to that reported in large national studies [7, 14]. Only one participant was excluded from this study due to missing diagnostic data. Prospective falls data were rigorously collected and recorded on standardised forms, reducing the probability of recall bias and underreporting. The use of MAR sheets, used by care home staff to administer drugs, provided reliable data on medications prescribed and taken. Limitations associated with the use of MAR sheets are that the duration of drug prescription cannot be ascertained from these and that drugs could have been changed during the three months of follow-up. It was not possible in our analysis to account fully for the influence of individual or combined comorbidities. Medical conditions, for instance arthritis, may affect postural stability and gait more than the drugs given for them. We did not include functional impairment in our model; this has the potential to 
confound our analysis, for example, if antipsychotics were predominantly prescribed in people who were bed or chairbound. We also did not collate data on drug dosage and this might reasonably have been expected to influence the likelihood of falls. Dementia severity was not recorded as part of the FINCH study - cognitive testing was not part of the protocol and care home records do not record dementia severity well. It is, however, unlikely that dementia severity will have confounded our analysis, as both falls and antipsychotic prescribing increase as dementia progresses, and confounding due to dementia severity would, if anything, have increased the strength of association between antipsychotic prescribing and falls.

The work replicates the findings of research undertaken in care home populations internationally that found an association between risk of falling and the number of drugs used $[15,16]$. Our findings show that the association between falls and psychotropic prescriptions is as strong in the UK care home population as it is in nursing homes internationally and non-care home settings $[3,8,17,18]$. In our study, falls were associated with antidepressants and benzodiazepines, but not with antipsychotics. Both antidepressants and benzodiazepines have been shown to increase fall risk in US nursing homes, and prescribers should include falls risk in their decision-making process when prescribing these drugs $[19,20]$. Our findings should not be interpreted to conclude that antipsychotics are safe, but simply that we did not observe a risk of falls associated with them; these drugs have other risks. Although antipsychotics were prescribed to a greater proportion of fallers than non-fallers, the lack of association between falls and antipsychotics was unexpected and differed from published literature [21-23]. UK national policies, such as the National Dementia Strategy, may have led to more appropriate prescribing of antipsychotics to care home residents with multiple falls risk factors, including dementia and wandering behaviours [24].

In conclusion, our findings show that care home residents are at increased risk of falls when they take more medications and when they take antidepressants and benzodiazepines. This supports judicious deprescribing using validated tools [25, 26]. Antidepressants and benzodiazepines should be used only when absolutely indicated. They should be appropriately tapered to cessation as soon as possible. The verdict on antipsychotics is less clear, but the findings presented here are not sufficient to recommend that they are used with anything other than caution. Providing adequate training and staffing levels to support non-pharmacological approaches to both depression and behavioural symptoms in care homes seems the most rational approach. These competencies are still underdeveloped in long-term care. Building them will enable more multidisciplinary approaches to prescribing and deprescribing, ensuring that drugs are only used where they can add value, and any attendant risks are minimised [27].

Acknowledgements Thank you to the Falls in Care Homes trial participants, researchers, Norwich Clinical Trials Unit, Dr. Jane Horne for helping with data transfer, and Mrs. Maureen Godfrey.

Author contributions All authors met the requirements for authorship as defined by the ICMJE; in that, all authors made substantial contributions to the conception or design of the work; or the acquisition, analysis, or interpretation of data for the work; contributed to the drafting the work and revising it critically for important intellectual content; approved the final approval of the version submitted here; and have agreed to be accountable for all aspects of the work in ensuring that questions related to the accuracy or integrity of any part of the work are appropriately investigated and resolved.

Funding This paper presents independent research funded by the National Institute for Health Research (NIHR) under its Health Research HTA programme (13/115/29). The views expressed are those of the author(s) and not necessarily those of the NHS, the NIHR or the Department of Health.

Availability of data and material Data used for this study are available from Professor Logan on request.

\section{Compliance with ethical standards}

Conflict of interest The authors have no conflicts of interest to declare.

Ethics approval Approval was received from the Yorkshire \& The Humber-Bradford Leeds Research Ethics Committee on 11/04/2016 (Ref: 16/YH/0111).

Informed consent Informed consent for the trial was obtained from participants, or a consultee if participants lacked capacity.

Consent for publication Paper was discussed in Trial Management Group (TMG) Meetings and sent to both TMG and NIHR.

Open Access This article is licensed under a Creative Commons Attribution 4.0 International License, which permits use, sharing, adaptation, distribution and reproduction in any medium or format, as long as you give appropriate credit to the original author(s) and the source, provide a link to the Creative Commons licence, and indicate if changes were made. The images or other third party material in this article are included in the article's Creative Commons licence, unless indicated otherwise in a credit line to the material. If material is not included in the article's Creative Commons licence and your intended use is not permitted by statutory regulation or exceeds the permitted use, you will need to obtain permission directly from the copyright holder. To view a copy of this licence, visit http://creativecommons.org/licenses/by/4.0/.

\section{Appendices}

\section{Appendix A}

See Fig. 1. 
Fig. 1 Signed data access form

NORWICH CTU

\section{Dataset Request Form \\ $\mathrm{FinCH}$}

\begin{tabular}{|l|r|}
\hline \multicolumn{2}{|c|}{ Request details } \\
\hline Data requested by: & Madeline Izza \\
\hline Date: & $\mathbf{0 3 / 1 0 / 2 0 1 8}$ \\
\hline Details of dataset required: & Baseline medications, baseline falls, \\
& baseline demographics. \\
& \\
\hline Method: & Read only access to database $: \square$ \\
& Data extracted to spreadsheet : $\checkmark$ \\
& Other (please give details below) : \\
\hline Send file/details to: & \\
\hline
\end{tabular}

\section{Completion details (Data Management Team use)}

\begin{tabular}{|c|c|}
\hline User name (for read only access): & Not required \\
\hline Data query details (for data extraction): & 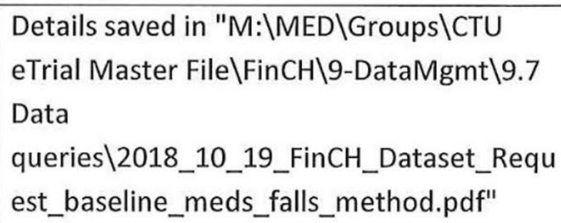 \\
\hline $\begin{array}{l}\text { Data saved at (location and filename) } \\
\text { (filename should include recipients initials } \\
\text { and date): }\end{array}$ & FinCH TMF 9.8, FinCH Data for MI [date] \\
\hline Completed by: & Claire West \\
\hline Date: & $19 / 10 / 2018$ \\
\hline
\end{tabular}

\section{Appendix B}

See Table 4. 
Table 4 Psychotropic medication classificationthose highlighted in bold were found in the data set

\begin{tabular}{|c|c|c|c|c|}
\hline Name & ATC code & Class & Subgroup & Group \\
\hline $\begin{array}{l}\text { Oxazepam } \\
\text { Lorazepam } \\
\text { Lormetazepam } \\
\text { Temazepam } \\
\text { Midazolam } \\
\text { Loprazolam }\end{array}$ & $\begin{array}{l}\text { N05BA04 } \\
\text { N05BA06 } \\
\text { N05CD06 } \\
\text { N05CD07 } \\
\text { N05CD08 } \\
\text { N05CD11 }\end{array}$ & Short-acting benzodiazepines & Benzodiazepines & Psychotropic \\
\hline $\begin{array}{l}\text { Clonazepam } \\
\text { Diazepam } \\
\text { Chlordiazepoxide } \\
\text { Clobazam } \\
\text { Flurazepam } \\
\text { Nitrazepam }\end{array}$ & $\begin{array}{l}\text { N03AE01 } \\
\text { N05BA01 } \\
\text { N05BA02 } \\
\text { N05BA09 } \\
\text { N05CD01 } \\
\text { N05CD02 }\end{array}$ & Long-acting benzodiazepines & & \\
\hline $\begin{array}{l}\text { Zopiclone } \\
\text { Zolpidem } \\
\text { Zaleplon }\end{array}$ & $\begin{array}{l}\text { N05CF01 } \\
\text { N05CF02 } \\
\text { N05CF03 }\end{array}$ & Benzodiazepine related drugs & & \\
\hline $\begin{array}{l}\text { Chlorpromazine } \\
\text { Levomepromazine } \\
\text { Promazine } \\
\text { Fluphenazine } \\
\text { Perphenazine } \\
\text { Prochlorperazine } \\
\text { Trifluoperazine } \\
\text { Periciazine } \\
\text { Haloperidol } \\
\text { Benperidol } \\
\text { Droperidol } \\
\text { Flupentixol } \\
\text { Zuclopenthixol } \\
\text { Pimozide } \\
\text { Loxapine }\end{array}$ & $\begin{array}{l}\text { N05AA01 } \\
\text { N05AA02 } \\
\text { N05AA03 } \\
\text { N05AB02 } \\
\text { N05AB03 } \\
\text { N05AB04 } \\
\text { N05AB06 } \\
\text { N05AC01 } \\
\text { N05AD01 } \\
\text { N05AD07 } \\
\text { N05AD08 } \\
\text { N05AF01 } \\
\text { N05AF05 } \\
\text { N05AG02 } \\
\text { N05AH01 }\end{array}$ & Typical antipsychotics & Antipsychotics & \\
\hline $\begin{array}{l}\text { Lurasidone } \\
\text { Clozapine } \\
\text { Olanzapine } \\
\text { Quetiapine } \\
\text { Asenapine } \\
\text { Sulpiride } \\
\text { Amisulpride } \\
\text { Risperidone } \\
\text { Aripiprazole } \\
\text { Paliperidone }\end{array}$ & $\begin{array}{l}\text { N05AE05 } \\
\text { N05AH02 } \\
\text { N05AH03 } \\
\text { N05AH04 } \\
\text { N05AH05 } \\
\text { N05AL01 } \\
\text { N05AL05 } \\
\text { N05AX08 } \\
\text { N05AX12 } \\
\text { N05AX13 }\end{array}$ & Atypical antipsychotics & & \\
\hline $\begin{array}{l}\text { Imipramine } \\
\text { Clomipramine } \\
\text { Trimipramine } \\
\text { Lofepramine } \\
\text { Amitriptyline } \\
\text { Nortriptyline } \\
\text { Doxepin } \\
\text { Dosulepin }\end{array}$ & $\begin{array}{l}\text { N06AA02 } \\
\text { N06AA04 } \\
\text { N06AA06 } \\
\text { N06AA07 } \\
\text { N06AA09 } \\
\text { N06AA10 } \\
\text { N06AA12 } \\
\text { N06AA16 }\end{array}$ & Tricyclic antidepressants & Antidepressants & \\
\hline $\begin{array}{l}\text { Fluoxetine } \\
\text { Citalopram } \\
\text { Paroxetine } \\
\text { Sertraline } \\
\text { Fluvoxamine } \\
\text { Escitalopram }\end{array}$ & $\begin{array}{l}\text { N06AB03 } \\
\text { N06AB04 } \\
\text { N06AB05 } \\
\text { N06AB06 } \\
\text { N06AB08 } \\
\text { N06AB10 }\end{array}$ & $\begin{array}{l}\text { Selective serotonin reuptake inhibitors } \\
\text { (SSRIs) }\end{array}$ & & \\
\hline $\begin{array}{l}\text { Isocarboxazid } \\
\text { Phenelzine } \\
\text { Tranylcypromine }\end{array}$ & $\begin{array}{l}\text { N06AF01 } \\
\text { N06AF03 } \\
\text { N06AF04 }\end{array}$ & Monoamine oxidase inhibitors & & \\
\hline $\begin{array}{l}\text { Moclobemide } \\
\text { Tryptophan } \\
\text { Mianserin } \\
\text { Trazodone } \\
\text { Minaprine } \\
\text { Bifemelane } \\
\text { Viloxazine } \\
\text { Mirtazapine } \\
\text { Bupropion } \\
\text { Venlafaxine } \\
\text { Reboxetine } \\
\text { Duloxetine } \\
\text { Agomelatine } \\
\text { Vortioxetine }\end{array}$ & $\begin{array}{l}\text { N06AG02 } \\
\text { N06AX02 } \\
\text { N06AX03 } \\
\text { N06AX05 } \\
\text { N06AX07 } \\
\text { N06AX08 } \\
\text { N06AX09 } \\
\text { N06AX11 } \\
\text { N06AX12 } \\
\text { N06AX16 } \\
\text { N06AX18 } \\
\text { N06AX21 } \\
\text { N06AX22 } \\
\text { N06AX26 }\end{array}$ & Other antidepressants & & \\
\hline
\end{tabular}




\section{References}

1. Dhalwani NN, Fahami R, Sathanapally H, Seidu S, Davies MJ, Khunti K (2017) Association between polypharmacy and falls in older adults: a longitudinal study from England. BMJ Open 7(10): 016358

2. Leipzig RM, Cumming RG, Tinetti ME (1999) Drugs and falls in older people: a systematic review and meta-analysis: I. Psychotropic drugs. J Am Geriatr Soc 47(1):30-39

3. National Institute for Health and Care Excellence (2013) Falls: assessment and prevention of falls in older people. National Institute for Health and Care Excellence, Manchester

4. Department of Health (2009) Falls and fractures: effective interventions in health and social care. Department of Health

5. Shah SM, Carey IM, Harris T, Dewilde S, Cook DG (2012) Quality of prescribing in care homes and the community in England and Wales. Br J General 1 Pract: J R College General Pract 62(598):e329-e336

6. Seitz D, Purandare N, Conn D (2010) Prevalence of psychiatric disorders among older adults in long-term care homes: a systematic review. Int Psychogeriatr 22(7):1025-1039

7. Gordon AL, Franklin M, Bradshaw L, Logan P, Elliott R, Gladman JRF (2014) Health status of UK care home residents: a cohort study. Age Ageing 43(1):97-103

8. Cox CA, van Jaarsveld HJ, Houterman S, van Der Stegen JCGH, Wasylewicz ATM, Grouls RJE et al (2016) Psychotropic drug prescription and the risk of falls in nursing home residents. J Am Med Direct Assoc 17(12):1089-1093

9. Hofmann H, Hahn S (2014) Characteristics of nursing home residents and physical restraint: a systematic literature review. J Clin Nurs 23(21-22):3012-3024

10. Logan PA, McCartney K, Armstrong S, Clark A, Darby J, Conroy $S$ et al (2019) Evaluation of the guide to action care home fall prevention programme in care homes for older people: protocol for a multi-centre, single blinded, cluster randomised controlled trial (FinCH). East Midlands Research into Ageing Network (EMRAN) Discussion Paper Series, vol 25, no. 1, pp. 1-44. https ://www.nottingham.ac.uk/emran/documents/issue-25-emran-feb2019.pdf. Accessed 26th June 2020

11. Gnjidic D, Hilmer SN, Blyth FM, Naganathan V, Waite L, Seibel MJ et al (2012) Polypharmacy cutoff and outcomes: five or more medicines were used to identify community-dwelling older men at risk of different adverse outcomes. J Clin Epidemiol 65(9):989-995

12. Lamb SE, Jørstad-Stein EC, Hauer K, Becker C (2005) Development of a common outcome data set for fall injury prevention trials: the prevention of falls network Europe consensus. J Am Geriatr Soc 53(9):1618-1622

13. Walker GM, Armstrong S, Gordon AL, Gladman JRF, Robertson $\mathrm{K}$, Ward $\mathrm{M}$ et al (2016) The falls in care home study: a feasibility randomized controlled trial of the use of a risk assessment and decision support tool to prevent falls in care homes. Clinical Rehabilitation. 30(10):973-983

14. Quince C (2013) Low expectations: attitudes on choice, care and community for people with dementia in care homes. Alzheimer's Society, London
15. Damián J, Pastor-Barriuso R, Valderrama-Gama E, de PedroCuesta J (2013) Factors associated with falls among older adults living in institutions. BMC Geriatr 13(1):6

16. Bor A, Matuz M, Csatordai M, Szalai G, Balint A, Benko R et al (2017) Medication use and risk of falls among nursing home residents: a retrospective cohort study. Int J Clin Pharmacol 39(2):408-415

17. Park H, Satoh H, Miki A, Urushihara H, Sawada Y (2015) Medications associated with falls in older people: systematic review of publications from a recent 5-year period. Eur J Clin Pharmacol 71(12):1429-1440

18. Woolcott JC, Richardson KJ, Wiens MO, Patel B, Marin J, Khan KM et al (2009) Meta-analysis of the impact of 9 medication classes on falls in elderly persons. Arch Intern Med 169(21):1952-1960

19. Thapa PB, Gideon P, Cost TW, Milam AB, Ray WA (1998) Antidepressants and the risk of falls among nursing home residents. N Engl J Med 339(13):875

20. Ray WA, Thapa PB, Gideon P (2000) Benzodiazepines and the risk of falls in nursing home residents. J Am Geriatr Soc 48(6):682-685

21. Janus S, Reinders G, Manen J, Zuidema S, Ijzerman M (2017) Psychotropic drug-related fall incidents in nursing home residents living in the Eastern part of the Netherlands. Drugs R\&D 17(2):321-328

22. Bozat-Emre S, Doupe M, Kozyrskyj AL, Grymonpre R, Mahmud SM (2015) Atypical antipsychotic drug use and falls among nursing home residents in Winnipeg, Canada. Int J Geriatr Psychiatry 30(8):842-850

23. Sterke SC, Van Beeck FE, Van Der Velde WNN, Ziere JMG, Petrovic JMM, Looman JMC et al (2012) New insights: doseresponse relationship between psychotropic drugs and falls: a study in nursing home residents with dementia. J Clin Pharmacol 52(6):947-955

24. Banerjee S (2010) Living well with dementia-development of the national dementia strategy for England. Int J Geriatr Psychiatry 25(9):917-922

25. O'Mahony D, O'Sullivan D, Byrne S, O'Connor MN, Ryan C, Gallagher P (2015) STOPP/START criteria for potentially inappropriate prescribing in older people: version 2. Age Ageing $44: 213-218$

26. Frank C, Weir E (2014) Deprescribing for older patients. CMAJ 186:1369-1376

27. Gutiérrez-Valencia M, Martínez-Velilla N, Vilches-Moraga A (2019) Polypharmacy in older people: time to take action. Eur Geriatr Med 10:1-3

Publisher's Note Springer Nature remains neutral with regard to jurisdictional claims in published maps and institutional affiliations. 